\title{
Implanted bisphosphonates in bone cement affect bone markers in rat serum
}

\author{
Tomasz Mazurkiewicz • Lukasz Matuszewski • \\ Anna Matuszewska $\cdot$ Magdalena Jaszek
}

Received: 7 November 2012 / Accepted: 26 January 2013 / Published online: 13 February 2013

(C) The Author(s) 2013. This article is published with open access at Springerlink.com

\begin{abstract}
Purpose Bisphosphonates (BPs) are antiresorptive drugs that provide important effects on bone turnover. The key to the high efficiency of BPs is their affinity for bone tissue, and their chemical structure provides their molecular mechanism of action. BPs are widely used to treat a variety of diseases that cause excess bone resorption, such as bone metastasis, hypercalcaemia due to malignancy and Paget's disease. The goal of this study was to assess whether the bisphosphonate (Pamifos ${ }^{\circledR}$ ) present in bone cement has any effect on bone turnover. In this paper, we present changes in cytokine levels in the serum of rats treated surgically. Methods Research was performed on 40 adult male Wistar rats. The rats were divided into four groups: two control groups $(\mathrm{A}, \mathrm{B})$ and two experimental groups $(\mathrm{C}, \mathrm{D})$. Bone in rats in the experimental groups was implanted with BPenriched cement, whereas bone in control-groups rats was implanted with clean cement (without BPs).

Results We found a higher concentration of tumour necrosis factor alpha (TNF- $\alpha)$ three weeks after surgery in rats implanted with BP-enriched cement compared with rats implanted with clean cement. After six weeks of treatment, TNF- $\alpha$ levels decreased significantly in rats treated with BP-enriched cement, whereas the control group experienced an increase in TNF- $\alpha$. The concentration of osteoprotegerin ligand (OPG) was higher in rats with BP implants. We found
\end{abstract}

Ł. Matuszewski $(\square)$

Pediatric Orthopedic and Rehabilitation Clinic, Medical University of Lublin, Lublin, Poland

e-mail: lukasz.matuszewski@am.lublin.pl

A. Matuszewska $\cdot$ M. Jaszek

Biochemistry Department, Maria-Curie Sklodowska University of Lublin, Lublin, Poland

T. Mazurkiewicz

Orthopedic and Traumatology Department, Medical University of Lublin, Lublin, Poland high levels of receptor activator of nuclear factor kappa-B ligand (RANKL) in rats after implantation of cement without BP in both groups.

Conclusions We conclude that use of bisphosphonate $\left(\right.$ Pamifos $^{\mathbb{R}}$ ), which is present in bone cement, has an effect on bone turnover in that BPs stimulate an increase in OPG and a decrease in RANKL in the bone microenvironment and thus may be an important component of mechanisms that reduce bone resorption. Therefore, the use of BPenriched cement implants appears to be justified.

\section{Introduction}

Bisphosphonates (BPs) are antiresorptive drugs that provide an important effect on bone turnover. There are increasing reports of the beneficial action of BPs not only on achieving better bone mineral density (BMD) but also on improving bone microarchitecture, strength and, consequently, quality. The key to the high efficiency of BPs is its affinity for bone tissue, and their chemical structure provides their molecular mechanism of action. BPs are stable pyrophosphate analogues with a phosphorus-carbon-phosphorus (P-C-P) structure that have a high affinity for hydroxyapatite (calcium ions) [1]. BPs are also potent inhibitors of bone resorption [2] and are widely used to treat a variety of diseases that cause excess bone resorption, such as bone metastasis, hypercalcaemia from malignancy and Paget's disease [3, 4]. It has been demonstrated that several types of BPs are useful for treating postmenopausal and other forms of osteoporosis $[5,6]$. BPs are classified into two groups, nitrogencontaining bisphosphonates (NBPs) and non-NBPs, each with different mechanisms of action. NBPs, such as alendronate, risedronate, ibandronate and pamidronate (PAM), act on the cholesterol pathway by inhibiting diphosphate synthase in the mevalonate pathway $[7,8]$. The non-NBPs, such as clodronate and etidronate, are transformed metabolically 
into cytotoxic adenosine triphosphatase (ATP) analogues that inhibit ATP-dependent intracellular enzymes [9]. Because BPs have an affinity for bone mineral, they act specifically on bone. During bone resorption by osteoclasts, the ingestion of BPs interferes with specific intracellular processes, which impair osteoclast function and ultimately cause apoptosis or cell death [10]. BPs that resemble pyrophosphate more closely (e.g. clodronate) can be incorporated into nonhydrolysable analogues of ATP that may inhibit ATP-dependent intracellular enzymes. NBPs (e.g. alendronate) inhibit enzymes in the mevalonate pathway, thereby preventing biosynthesis of essential compounds for protein prenylation, which blocks the function of key regulate proteins [11]. Some studies suggest that BPs that resemble the pyrophosphate group have antiinflammatory effects, whereas aminobisphosphonates have some proinflammatory effects [12]. In summary, BPs regulate osteoblastic functions such as proliferation and differentiation, prevent osteoblast apoptosis, modulate osteoblastic production of extracellular matrix proteins and regulate osteoblastic expression and secretion of various growth factors and cytokines [13].

Several recent studies, both preclinical and clinical, have focused on the potential application of BPs to the problems of bone catabolism encountered in orthopaedics. These studies indicate that the most promising roles for BPs are prevention of bone collapse following osteonecrosis and in enhancing implant fixation. Combination therapies that have both bone antiresorptive and anabolic agents also show great promise for orthopaedic applications [14].

The microarchitectural adaptation of bone mass and BMD due to osteoclast-mediated resorption is of great clinical importance for many bone diseases, including osteoporosis and osteoarthritis. During bone resorption, trabecular bone microstructure is altered, often influencing functional strength and the integrity of cartilage support. Osteoclast formation (osteoclastogenesis) is induced in the presence of macrophage colony stimulating factor (M-CSF) when the membrane-bound factor receptor activator of nuclear factor kappa-B ligand (RANKL) binds to its receptor, RANK. RANKL is a protein of 317 amino acids that belongs to the tumour necrosis factor (TNF) superfamily and the messenger RNA (mRNA) of which is largely expressed in bone, bone marrow and lymphoid tissues. The predominant role of this cytokine in bone physiology is the stimulation of osteoclastic differentiation/activation and the inhibition of osteoclast apoptosis [15]. The process of osteoclastogenesis can be disturbed by local factors that interrupt RANKL-RANK intercellular signalling [16]. One of these factors is OPG, a soluble, circulating glycoprotein from the TNF-receptor family. OPG present in an extracellular matrix can inhibit osteoclastogenesis by binding with RANKL and blocking its interaction with RANK on osteoclast precursors. OPG blocks osteoclast differentiation, promotes apoptosis of activated osteoclasts and reduces osteoclast adhesion to the bone surface, with a net effect of reduced osteoclast activity [17-19]. TNF- $\alpha$ exerts its biological effects by binding to TNF type 1 receptor (TNF-R1) and type 2 receptor (TNFR2) $[20,21]$. Both receptors are expressed in the lineages of osteoclasts and osteoblasts [22]. TNF- $\alpha$ plays a central role for inflammatory reaction $[23,24]$.

The goal of this study was to assess whether the bisphosphonate (Pamifos ${ }^{\circledR}$ ) that is present in bone cement has any effect on bone turnover. In this paper, we present changes in cytokine levels in the serum of rats treated surgically. Anaesthetised rats were injected with cement that was enriched with a BP.

\section{Materials and methods}

Animals Wistar CRL(WI)WU BR rats were obtained from Mossakowski Medical Research Centre, Polish Academy of Sciences. The experimental procedures were reviewed and approved by the Bioethical Committee of Animal Experimentation of the Medical University of Lublin.

Reagents Enzyme-linked immunosorbent assay (ELISA) kits were purchased from BioVendor Research and Diagnostic Products (Brno, Czech Republic). Bisphosphonate (Pamifos 60) was purchased from Vipharm (Warsaw, Poland). Bone cement was purchased from CMW 1, DePuy International Ltd, England.

Animal model Research was performed on 40 adult male Wistar rats, the weight of which ranged from $120 \mathrm{~g}$ to $240 \mathrm{~g}$. The rats were divided into four groups: two control groups $(\mathrm{A}, \mathrm{B})$ and two experimental groups $(\mathrm{C}, \mathrm{D})$. Bone in rats in experimental groups was implanted with BP-enriched cement and in the control groups with clean bone cement (without BP). Because experimental groups were operated upon at a different time, each group had its own dedicated control group. The animals were anaesthetised using thiopental with depth of anaesthesia being assessed by pedal reflex. Each animal was then placed in the supine position, and the skin over both tibial bones was shaved and disinfected. A skin incision was made over the proximal part of the tibial bone. After exposure of the proximal tibia, freshly mixed bone cement was pressurised into the bone canal through a predrilled hole by using a syringe with a modified needle. Twenty rats were given pure cement (control groups) and the remaining 20 rats cement mixed with BP. The wound was closed using Vicryl sutures and staples. At three and six weeks after surgery, the rats were anaesthetised using thiopental $(30 \mathrm{mg} / \mathrm{kg})$, and blood samples were taken from the left ventricle. The samples were frozen in liquid nitrogen and stored at $-70{ }^{\circ} \mathrm{C}$. 
Blood assays To determine biochemical markers, blood samples were taken from the heart, preferably the ventricle, and then punctured into pyrogen-free tubes containing heparin (Endo Tube ET; Chromogenix, Mo" Indal, Sweden). Plasma was immediately separated at $4{ }^{\circ} \mathrm{C}$ by centrifugation at $180 \mathrm{~g}$ for ten minutes and stored in pyrogen-free tubes (N201 Test Tubes; Biowittaker, Walkersville, MD, USA) at $-80{ }^{\circ} \mathrm{C}$. TNF- $\alpha$, osteoprotegerin and rat soluble RANKL (sRANKL) concentrations in blood serum were analysed using an ELISA kit.

\section{Statistical analysis}

Statistical analyses were performed using one-way analyses of variance (ANOVA). Post-hoc comparison of means was carried out with Tukey's test for multiple comparisons, when appropriate. For this case, all data are shown as the means \pm standard error (SEM). For cases with rejected hypothesis of normal distribution or homogeneity of variance, nonparametric Kruskal-Wallis ANOVA by Ranks multiple comparisons was used. Data are shown as median with first and third quartiles. Data were considered statistically significant at a confidence limit of $P<0.05$. All statistical calculations were performed using 10.0 STATISTICA software (StatSoft, Poland).

\section{Results}

We found a higher concentration of TNF- $\alpha$ three weeks after surgery in rats implanted with BP-enriched cement compared with rats implanted with cement without BP. After six weeks of treatment TNF- $\alpha$ levels decreased significantly in rats treated with a BP-enriched cement, whereas rats in the control groups experienced an increase in TNF- $\alpha$ (Fig. 1). The result

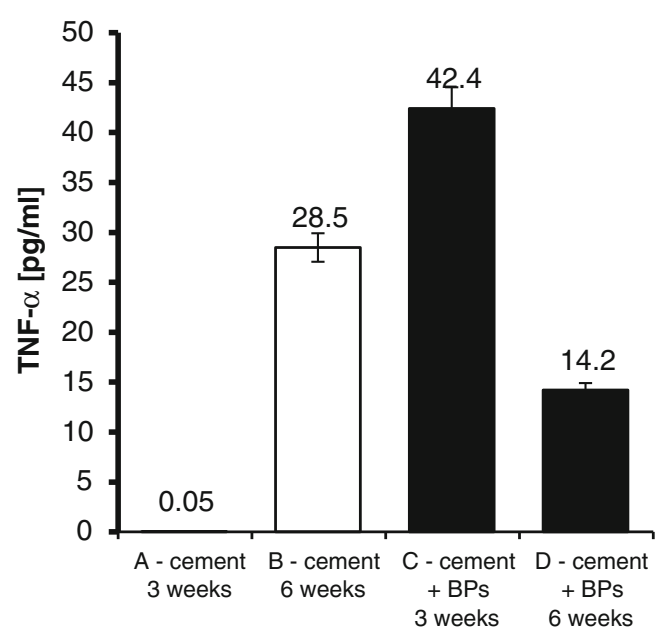

Fig. 1 Median level of tumour necrosis factor alpha (TNF- $\alpha$ ) concentration in rats' serum after clean cement was implanted into the bone (a, b) in comparison with rats implanted with bisphosphonate (BP)enriched cement $(\mathbf{c}, \mathbf{d})$

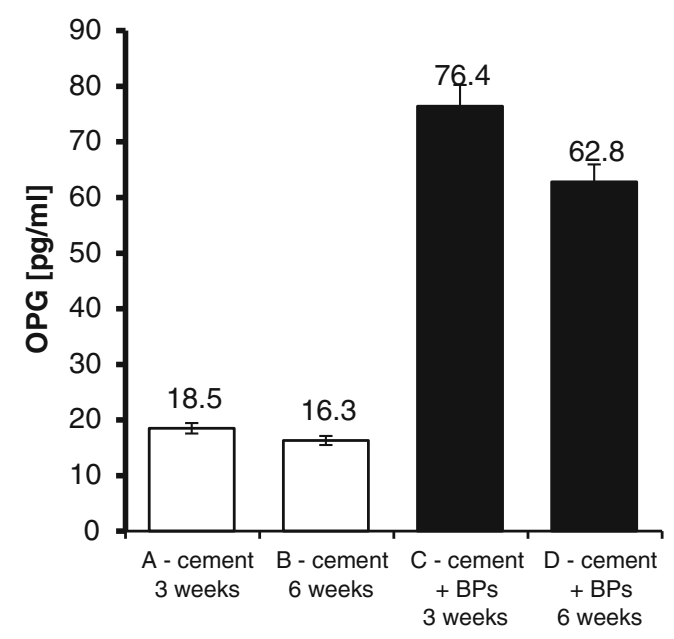

Fig. 2 Median level of osteoprotegerin (OPG) concentration in rats' serum after bone implantation with clean cement $(\mathbf{a}, \mathbf{b})$ in comparison with rats implanted with bisphosphonate (BP)-enriched cement $(\mathbf{c}, \mathbf{d})$

is highly statistically significant $(P=0.00)$. Post-hoc RIR Tukey test was used to verify differences between groups. Statistically significant differences between the groups studied using BPs with cement were found three and six weeks after surgery $(P=0.000132)$. There were also statistically significant differences between the control group and a BP group six weeks after surgery $(P=0.000127)$.

The results of the Kruskal-Wallis test $[\mathrm{H}(3, n=40)=$ 32.13, $P=0.00$ ] indicate a statically significant difference between the level of OPG in the treatment groups. The concentration of OPG, a natural antagonist of RANKL, was higher in rats with BP implants (at both three and six weeks after surgery) than in the control groups (Fig. 2) . OPG level in the control group three weeks after the treatment was significantly lower than in the test group with BP implants $(P=0.000101)$. Similar results were obtained six weeks after surgery, where the level of OPG in the control group was significantly lower than in the study group $(P=0.004897)$. Three weeks after the treatment, the OPG concentration was four times higher in rats implanted with cement containing BP (group C) than in the control group (group A).

As described earlier in the paper, there was a statistically significant difference in RANKL level, as we found high levels of RANKL in rats after implantation of cement without BP in both groups (A and B, Fig. 3). The highest RANKL concentration, $8.23 \pm 0.97 \mathrm{pg} / \mathrm{ml}$, was found six weeks after surgery in the control group (B, $P=0.00002)$.

\section{Discussion}

For healthy bone, the processes of the bone formation and resorption should be in balance, thus guaranteeing relatively constant bone mass. Regulation of the bone remodelling 


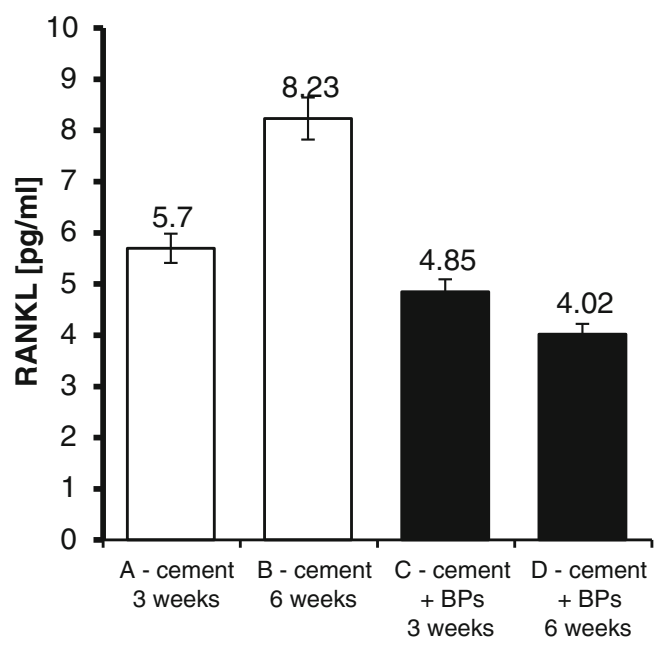

Fig. 3 Median level of receptor activator of nuclear factor kappa-B ligand (RANKL) concentration in rats' serum after bone implantation with clean cement $(\mathbf{a}, \mathbf{b})$ in comparison with rats implanted with bisphosphonate (BP)-enriched cement (c, d)

process involves hormones and local mediators (growth factors and cytokines) secreted by osteoblasts and osteoclasts. The local cytokine secretion may produce locally high concentrations, so that they become effective [25]. Identification of the OPG/RANKL/RANK system as an important mediator of osteoclastogenesis is a great achievement in the field of bone biology.

OPG is one factor inhibiting bone resorption; thus, when its concentration is reduced, the resorption processes may prevail and bone loss occurs. Bucay et al. reported that mice lacking the $O P G$ gene developed severe osteoporosis, with multiple fractures and associated hypercalcaemia [26]. Recent in vitro studies have clearly demonstrated that osteoblastic lineage cells are targets for BPs and that these compounds act to modulate important cellular functions of osteoblasts, including proliferation, differentiation, synthesis of extracellular matrix proteins and formation of mineralised nodules [27-29]. Earlier coculture studies have suggested that the presence of osteoblastic lineage cells is required in order for the antiresorptive effects of BPs to occur [30] and proposed that this effect depends upon a soluble factor that is secreted by osteoblasts and acts on osteoclasts to inhibit their function, based on the capacity of BP-conditioned osteoblastic medium to inhibit osteoclast formation and activity [31, 32].

RANKL is both necessary and sufficient for osteoclast formation and activation, whereas OPG, which is secreted by osteoblastic lineage cells, blocks these effects by neutralising RANKL [33]. TNF exerts osteoclastogenic properties indirectly by stimulating RANKL in various cell types $[34,35]$.

Our study demonstrates that local BP treatment can affect the level of cytokines in the blood serum. We found low levels TNF- $\alpha$ in serum of rats six weeks after implantation into the bone of cement enriched with BP compared with three weeks after the surgery. Recent evidence suggests that $\mathrm{TNF}-\alpha$ is not exclusively a catabolic modulator of bone metabolism. Balga et al. described TNF- $\alpha$ as acting not only as a stimulator of bone resorption but also as a possible inhibitor for the development of osteoclasts in vitro [36]. The decrease in TNF- $\alpha$ levels in rats treated with BP implants is therefore preferred for the process of bone formation, whereas the effect of lower concentrations were obtained when using only BP-enriched cement implants. In rats implanted with clean bone cement, TNF- $\alpha$ levels in serum six weeks after surgery significantly increased relative to the level observed three weeks after the operation.

The mutual activity of osteoclasts and osteoblasts ensures a balance between bone resorption and formation during the turnover of normal healthy bone. Osteoclast formation, function and survival are regulated primarily by RANKL and the two receptors to which it binds: RANK and OPG. In healthy bone, the RANKL pathway facilitates the balance between bone formation and resorption; however, an increase in the level of RANKL promotes bone resorption [37].

In our studies, we noted a reduction in RANKL serum levels in rats six weeks after implantation of cement containing BP compared with that recorded three weeks after surgery, whereas concentration in the control group increased from $5.7 \mathrm{pg} / \mathrm{ml}$ (three weeks after the operation) to $8.23 \mathrm{pg} / \mathrm{ml}$ (six weeks after the operation). There was also a high level of OPG in serum both three and six weeks after implantation of bone cement enriched with BP, whereas in controls, OPG concentration was maintained at a much lower level. Our results support the hypothesis that cement enriched with BP may regulate important mediators involved in osteoclastogenesis, such as RANKL synthesised by osteoblasts [38], and may modulate OPG, a decoy receptor of RANKL absorption, thus preventing RANK activation. Viereck et al. showed that the primary effect of BPs in differentiated osteoblasts on the RANKL/OPG system is the enhancement of OPG production [13]. They showed also that the BPs pamidronate and zoledronic acid act directly on human osteoblastic cells to increase OPG secretion, a potent inhibitor of bone resorption. Research by Aspenberg et al. and Jeppsson et al. showed that local used of a BP solution increased bone ingrowth or new bone formation [39, 40]. However, that did not present the humoral response.

We conclude that use of bisphosphonate (Pamifos ${ }^{\circledR}$ ) in bone cement has an effect on bone turnover. Stimulated by an increase in BP in OPG and a decrease in RANKL in bone microenvironment may be an important component of the mechanisms that reduce bone resorption. Therefore, the use of BP-enriched bonecement implants appears to be justified. 
Open Access This article is distributed under the terms of the Creative Commons Attribution License which permits any use, distribution, and reproduction in any medium, provided the original author(s) and the source are credited.

\section{References}

1. Fleisch H (1998) Bisphosphonates: mechanisms of action. Endcr Rev 19:80-100

2. Russell RGG, Rogers MJ (1999) Bisphosphonates: from the laboratory to the clinic and back again. Bone 25:97-106

3. Douglas DL, Russell RGG, Kanis JA, Preston CJ, Preston FE, Preston MA, Woodhead JS (1980) Effect of dichloromethylene diphosphonate in Paget's disease of bone and in hypercalcaemia due to primary hyperparathyroidism or malignat disease. Lancet $1: 10443-11047$

4. Mundy GR, Yoneda T (1998) Bisphosphonates as anticancer drugs. N Engl J Med 339:398-400

5. Watts NB, Harris ST, Genant HK, Wasnich RD, Miller PD, Jackson RD, Licata AA, Ross P, Woodson GC III, Yanover MJ, Mysiw WJ, Kohse L, Rao MB, Steiger P, Richmond B, Chesnut CH III (1990) Intermittent cyclical etidronate treatment of postmenopausal osteoporosis. N Engl J Med 323:7379

6. Saag KG, Emkey K, Schnitzer TJ, Brown JP, Hawkins F, Goemaere S, Thamsborg G, Liberman UA (1998) Alendronate for the prevention and treatment of glucocorticoid-induced osteoporosis. Glucocorticoid-induced osteoporosis intervention study group. N Engl J Med 339:292-299

7. Amin D, Cornell SA, Gustafson SK, Needle SJ, Ulich JW, Bilder GE, Perrone MH (1992) Bisphosphonates used for the treatment of bone disorders inhibit squalene synthase and cholesterol biosynthesis. J Lipid Res 33:1657-1663

8. Benfold HL, Frich JC, Auriola S, Monkkonen J, Rogers MJ (1999) Farnesol and geranylgeraniol prevent activation of caspases by aminobisphosphonates: biochemical evidence for two distinct pharmacological classes of bisphosphonate drugs. Mol Pharmacol $56: 131-140$

9. Frith JC, Monkkonen J, Blackburn GM, Russell RG, Rogers MJ (1997) Clodronate and liposome-encapsulated clodronate are metabolized to a toxic ATP analog, adenosine 5'-(beta, gammadichloromethylene) triphosphate, by mammalian cells in vitro. J Bone Miner Res 12:1358-1367

10. Russel R, Rogers M (1999) Bisphosphonates: from the laboratory to the clinic and back again. Bone 25(1):97-106

11. Åstrand J, Aspenberg P (2002) Reduction of instability-induced bone resorption using bisphosphonates. High doses are needed in rats. Acta Orthop Scand 73(1):24-30

12. Makkonen N, Hirvonen M-R, Teräväinen T, Savolainen K, Mönkönen J (1996) Different effects of three bisphosphonates on nitric oxide production by Raw 264 macrophage-like cells in vitro. J Pharmacol Exp Ther 277:1097-1102

13. Viereck V, Emons G, Lauck V, Frosch K-H, Blaschke S, Grundker C, Hofbauer L (2002) Bisphosphonates pamidronate and zoledronic acid stimulate osteoprotegerin production by primary human osteoblasts. Biochem Biophys Res Commun 291:680-686

14. Wilkinson JM, Little DG (2011) Bisphosphonates in orthopedic applications. Bone 49:95-102

15. Khosla S (2001) Minireview: the OPG/RANKL/RANK system. Endocrinology 142:5050-5055

16. Hsu H, Lacey DL, Dunstan CR (1999) Tumor necrosis factor receptor family member RANK mediates osteoclast differentiation and activation induced by osteoprotegerin ligand. Proc Natl Acad Sci U S A 96:3540-3545

17. O'Brien EA, Williams JH, Marshall MJ (2000) Osteoprotegerin ligand regulates osteoclast adherence to the bone surface in mouse calvaria. Biochem Biophys Res Commun 274:281-290

18. Lacey DL, Tan HL, Lu J (2000) Osteoprotegerin ligand modulates murine osteoclast survival in vitro and in vivo. Am J Pathol 157:435-448

19. Simonet WS, Lacey DL, Dunstan CR (1997) Osteoprotegerin: a novel secreted protein involved in the regulation of bone density. Cell 89:309-319

20. Gupta S (2001) Molecular steps of tumor necrosis factor receptor - mediated apoptosis. Curr Mol Med 1(3):317-324

21. Screaton G, Xu XN (2000) T cell life and death signaling via TNF-receptor family members. Curr Opin Immunol 12(3):316322

22. Teitelbaum SL (2006) Osteoclasts; culprits in inflammatory osteolysi. Arthritis Res Ther 8(1):201

23. Kitaura H, Sands MS, Aya K, Zhou P, Hirayama T, Uthgenannt B, Wei S, Takeshita S, Novack DV, Silva MJ, Abu-Amer Y, Ross FP, Teitelbaum SL (2004) Marrow stromal cells and osteoclast precursors differentially contribute to TNF-alpha-induced osteoclastogenesis in vivo. J Immunol 173(8):4838-4846

24. Wei S, Kitaura H, Zhou P, Ross FP, Teitelbaum SL (2005) Interleukin-1 mediates tumor necrosis factor-induced osteoclastogenesis. J Clin Invest 115:282-290

25. Ambroszkiewicz J, Gajewska J, Chełchowska M, Ołtarzewski M, Laskowska-Klita T, Nowacka M, Milanowski A (2008) Concentration of osteoprotegerin, bone formation and resorption markers in patients with phenylketonuria. Pol Merkur Lekarski XXV (145):57

26. Bucay N, Sarosi I, Dunstan CR (1998) Osteoprotegerin-deficient mice develop early onset osteoporosis and arterial calcification. Genes Dev 12:1260-1268

27. Reinholz GG, Getz B, Pederson L, Sanders ES, Subramaniam M, Ingle JN, Spelsberg TC (2000) Bisphosphonates directly regulate cell proliferation, differentiation, and gene expression in human osteoblasts. Cancer Res 60:6001-6007

28. Klein BY, Ben-Bassat H, Breuer E, Solomon V, Golomb G (1998) Structurally different bisphosphonates exert opposing effects on alkaline phosphatase and mineralization in marrow osteoprogenitors. J Cell Biochem 68:186-194

29. Giuliani N, Pedrazzoni M, Negri G, Passeri G, Impicciatore M, Girasole G (1998) Bisphosphonates stimulate formation of osteoblast precursors and mineralized nodules in murine and human bone marrow cultures in vitro and promote early osteoblastogenesis in young and aged mice in vivo. Bone 22:455-461

30. Sahni M, Guenther HL, Fleisch H, Collin P, Martin TJ (1993) Bisphosphonates act on rat bone resorption through the mediation of osteoblasts. J Clin Invest 91:2004-2011

31. Vitte C, Fleisch H, Guenther H (1996) Bisphosphonates induce osteoblasts to secrete an inhibitor of osteoclastmediated resorption. Endocrinology 137:2324-2333

32. Nishikawa M, Akatsu T, Katayama Y, Yasutomo Y, Kado S, Kugal N, Yamamoto M, Nagata N (1996) Bisphosphonates act on osteoblastic cells and inhibit osteoclast formation in mouse marrow cultures. Bone 18:9-14

33. Simonet WS, Lacey DL, Dunstan CR, Kelley M, Chang M-S, Luthy R, Nguyen HQ, Wooden S, Bennett L, Boone T, Shimamoto G, DeRose M, Eliott R, Colombero A, Tan H-L, Trail G, Sullivan J, Davy E, Bucay N, Renshaw-Gegg L, Hughes TM, Hill D, Pattison W, Campbell P, Sander S, Van G, Tarpley J, Derby P, Lee R, Amgen EST Program, Boyle WJ (1997) Osteoprotegerin: a novel secreted protein involved in the regulation of bone density. Cell 89:309-319 
34. Zhang YH, Heulsmann A, Tondravi MM, Mukherjee A, Abu-Amer Y (2001) Tumor necrosis factor- $\alpha$ (TNF) stimulates RANKL induced osteoclastogenesis via coupling of TNF type 1 receptor and RANK signaling pathways. J Biol Chem 276:563-568

35. Suda T, Udagawa N, Nakamura I, Miyaura C, Takahashi N (1995) Modulation of osteoclast differentiation by local factors. Bone 17(Suppl 2):87S-91S

36. Balga R, Wetterwald A, Portenier J, Dolder S, Mueller C, WiHofstetter W (2006) Tumor necrosis factor-alpha: alternative role as an inhibitor of osteoclast formation in vitro. Bone 39:325-335
37. Arnulf S (2009) RANK ligand: a key role in cancer-induced bone destruction? Eur Urol Suppl 8:823-828

38. Mackie PS (2001) Bisphosphonates regulate cell growth and gene expression in the UMR 106-01 clonal rat osteosarcoma cell line. Br J Cancer 84(7):951-958

39. Aspenberg A, Astrand J (2002) Bone allograft pretreated with bisphosphonate are not resorbed. Acta Ortop Scand 73(1):20-23

40. Jeppsson C, Astrand J, Tagil M, Aspenberg P (2003) A combination of bisphosphonate and BMP additives in impacted bone allografts. Acta Ortop Scand 74(4):483-489 